San Jose State University

From the SelectedWorks of Marjorie R. Freedman

2010

Implementing a Solid Waste Management Diversion Program in a Conventional Cook-Serve Hospital System: A Feasibility Study

Marjorie R. Freedman, San Jose State University

Irene Boyle Franklin, San Jose State University 


\section{Implementing a Solid Waste Management Diversion Program in a Conventional Cook-Serve Hospital System: A Feasibility Study}

Marjorie R. Freedman and Irene Boyle Franklin. Journal of Hunger and Environmental Nutrition, $5: 3,370-379$.

Americans generate over 250 million tons of Municipal Solid Waste ("trash") each year, with institutional facilities such as hospitals accounting for up to $45 \%$ of this waste. Solid waste diversion, through recycling and composting, decreases the waste sent to landfills. The objective of this feasibility study was to implement an integrated solid waste diversion program at a conventional cook-serve kitchen for a 250-bed hospital. The waste diversion program resulted in 1390 pounds of organic matter and recycling being diverted from landfills over 5 days. It is estimated that the continuing program will reduce landfill waste by 51 tons annually.

Key words: compost, recycling, solid waste management diversion, cook-serve kitchen, hospital

\section{INTRODUCTION}

The Environmental Protection Agency reports Americans generated 250 million tons of Municipal Solid Waste (MSW) in 2008, only about one third of which was diverted from landfills via recycling or composting. ${ }^{1}$ Institutional and commercial facilities, such as hospitals, prisons and schools, contribute up to $45 \%$ of that annual total MSW. ${ }^{1}$ Food waste is a large portion of MSW, constituting approximately $13 \%$ of residential, institutional, and commercial solid waste in the US, ${ }^{1}$ and $16 \%$ in California. ${ }^{2}$

Health Care Without Harm is an international organization seeking to improve the environment in medical institutions. ${ }^{3}$ Health Care Without Harm reports that a single medical center produces up to 6 tons of MSW daily, with approximately $20 \%$ originating from food service operations. ${ }^{4}$ Food-service MSW includes pre-consumer kitchen waste (all food waste generated prior to sale or use including improperly prepared or spoiled food, expired food and trim waste), post-consumer patient tray waste, and cafeteria waste.

Reducing food waste in medical institutions has become increasingly important due to concerns regarding economics, sustainability, and community health and nutrition. Implementing a sustainable solid waste reduction program lowers tipping fees (charged to dump trash at landfills and waste transfer stations), as waste removal costs are determined by volume. Sustainability is furthered by significant decreases in greenhouse gas emissions from the diversion of food waste from landfills to composting facilities, a process estimated to reduce up to 0.82 metric tons of carbon dioxide equivalent $\left(\mathrm{CO}_{2} \mathrm{E}\right)$ per ton of food waste. [Note: $\mathrm{CO}_{2} \mathrm{E}$ is used to compare emissions from different greenhouse gases based upon their climate changing potential.] ${ }^{5}$ Food waste recovery further supports community health and nutrition by "closing the food loop." Compost (made from food waste that is not edible) can be used for urban and regional agricultural production, and edible food "waste" may be re-distributed to persons suffering food insecurity. For example, Oakland Potluck is an organization that diverts edible food from the waste stream and donates the diverted food to local needy people. ${ }^{6}$

Despite the foregoing benefits, few hospitals are known to have any formal food waste diversion program or system. Of the over 5800 hospitals in the US, ${ }^{7}$ as of May $2010,5 \%(\mathrm{n}=291$ facilities) have committed to Health Care Without Harm's "Healthy Food in Health Care Pledge," which asks medical institutions to "minimize and beneficially reuse food waste." 8 Of 122 hospitals who participated in an earlier survey (May 2008), 60\% $(n=73)$ reported composting food waste with 41 hospitals reporting composting pre-consumer kitchen waste, 24 composting post-consumer patient tray waste, and 21 composting cafeteria food waste. The balance of facilities reported future plans to begin a food waste compost program. ${ }^{9}$ In a separate 2008 survey of 84 food service 
directors, fewer than 5\% $(\mathrm{n}=4)$ reported their facilities composted food waste (Personal Communication, November 19, 2009; E. Huang).

The low numbers of medical facilities adopting a food waste diversion program may be due to the challenges of separating, collecting, and processing solid food waste. ${ }^{10}$ Nevertheless, efforts to divert food waste in hospitals should be encouraged. Especially needed are publications of "best practices" that describe methods to train food service personnel to collect, sort and divert solid food waste. Notably, San Francisco recently adopted an ordinance requiring food waste diversion, ${ }^{11}$ and many other cities in the US and Canada have implemented diversion programs. ${ }^{12,13}$

To address the need for more medical institutions to implement food waste diversion programs, to reduce MSW sent to landfills and to meet city MSW diversion requirements, this project was designed to develop and implement a solid waste diversion system in a conventional cook-serve production kitchen for a 250-bed hospital in San Francisco. This paper describes: 1) the planning of the solid waste reduction program; 2) the training of food service personnel to implement the program; and 3) short-term results of the food diversion pilot program, along with projected long-term reductions in landfill waste. Although this project examined one medical facility, the results may be useful for analyzing and implementing waste diversion programs in other commercial and institutional settings.

\section{Facility Description}

\section{METHODS}

The setting for this intervention was a conventional cook-serve production kitchen at the 250-bed San Francisco VA Medical Center. This setting benefited from a well-developed municipal infrastructure, which made possible large scale off-site composting (including for meat and dairy products).

\section{Program Planning, Training, and Implementation}

This project was specifically designed to minimize initial labor and capital costs and took place over the summer of 2009. The project addressed food waste diversion in the food production, food tray line and dish cleaning areas, the last capturing patient tray waste. The project began with a non-formal solid waste audit (conducted by the Nutrition and Food Service and the Environmental Management Service departments) to determine food waste sources, estimate waste volumes, and identify resources available for collection and storage of food waste prior to municipal waste collection. The project coordinator (a dietetic intern) collaborated with the kitchen management and line staff to develop a system that could be easily integrated into the existing kitchen routine and layout. For example, location of waste collection containers was identified as critical, because the further kitchen staff had to walk to divert food waste for composting, the lower was program compliance.

Prior to program implementation, all 65 food service employees were oriented to the changes in procedure, educated about the benefits of composting, and trained on how to sort food waste (Table 1). The dietetic intern developed all educational materials and provided program support. Educational efforts aimed at motivating employees to implement the waste diversion program included discussing the environmental impact of composting and the importance of accurate sorting of waste to avoid contamination. Staff training on how to sort waste included a lesson on how to identify compostable and recyclable items, and how to properly store, handle, and dispose of the 3 categories of waste: (1) compostable (e.g., food, soiled paper, milk and juice cartons, waxed paper, degradable disposables, and tea bags); (2) recyclable (e.g., plastic bottles and containers, aluminum cans, foil, glass bottles, and rigid plastics); and (3) garbage (e.g., straws, plastic bags, condiment packages, plastic wrap, and snack bags). After training, each employee 
completed a written test, which was self-corrected. After incorrect answers were reviewed and discussed, employees were re-tested (per standard hospital employee training protocol), resulting in all employees scoring $100 \%$.

\section{TABLE 1: Lesson Plan Presented to Nutrition and Food Service Employees}

Title: Waste Disposal: Compost, Recycle \& Waste

Time: 25-30 minutes

Objectives: At the end of the class, employees will be able to:

1. Describe composting and recycling procedures.

2. Identify items; be able to describe the appropriate way to sort and dispose of each.

3. Discuss benefits of composting and recycling materials.

Materials:

- Compost bin and bag; recycling bin and bag; examples of items commonly found in kitchen destined for compost, recycling, and landfill

- Educational/descriptive handouts

- Appropriate number of post-tests and writing instruments

Lesson Plan Outline:

1. Discussion of why changes are being made

a. Benefits of Composting

1. Economic: tipping fees and cost saving to hospital.

2. Environmental: how composting allows reuse of otherwise discarded items and how through the process of decomposition, food waste is converted into a rich soil amendment, reduces methane gas emissions from landfills and reduces water use.

b. Compliance to current law: as part of a plan to completely stop sending waste to landfills and incinerators by 2020 , a city ordinance requires every residence and business in the city to separate refuse into recycling, compost, and trash. Businesses who fail to properly sort their refuse can be fined $\$ 500$ per incidence.

2. Demonstration of how to recycle metals, plastics, and cardboard

a. Show a prepared recycling can to be used in the kitchen and dish room areas. Describe the type of can (Blue toter) and appropriate bag (clear).

b. Discuss items appropriate for disposal in recycling bin (e.g., empty metal cans, empty plastic cups, empty plastic containers and unbroken glass).

c. Discuss items appropriate for standard cardboard recycling (clean boxes and paper). Describe process for cardboard boxes (breakdown - recycle clean, compost soiled).

d. Describe process for removal from kitchen and appropriate location for all recyclable materials on trash dock.

3. Demonstration of how to compost food, food soiled paper, and specialty products

a. Show a prepared composting can to be used in the kitchen and dish room areas. Describe they type of can (green toter), and the importance of using the biodegradable bags (single bag, tie and add new bag when $1 / 3$ full).

b. Discuss items appropriate for disposal in composting bin (e.g., solid food items, food soiled paper and biodegradable disposable items).

c. Discuss items NOT appropriate for composting (liquids and clean/non waxy cardboard).

d. Describe process for removal from kitchen and appropriate location for compostable materials to be taken out to on trash dock, movement and alternate location for cans on day(s) prior to scheduled pick-up.

4. Demonstration on what to do with garbage (all items that go to landfill)

a. Show a prepared garbage can to be used in the kitchen and dish room areas. Describe they type of can (aluminum can), and appropriate bag (clear). 
b. Discuss items appropriate for disposal in garbage bin (e.g., "mixed" items, nonrecyclable plastic/packaging and sharp items).

c. Describe process for removal from kitchen and appropriate location for landfill materials to be taken out to on trash dock.

5. Discussion of educational materials. Instruct: when in doubt, set the item aside, and check with the supervisor on duty.

6. Questions and Answers

7. Evaluation: Distribute quizzes and have each employee complete one. Once completed, review and discuss all answers so that each employee has a good understanding of the materials covered in the class.

8. Tour: Take participants to trash dock, show appropriate locations for delivery of composting, recycling, clean cardboard, and garbage. Dismiss when finished.

Visual training materials (posted and maintained near the dish room for ease of reference) included 3-D posters depicting examples of common compostable, recyclable, and garbage materials (Figure 1). Other program details, such as the proposed kitchen layout, samples of waste containers and bags, and the new compost hauler collection site, were discussed with kitchen administrators and service staff. Additional training included hands-on waste category item identification, and allotted time for feedback from kitchen staff to address their questions and concerns.

FIGURE 1. Posters Displaying Compostables, Recyclables and Waste
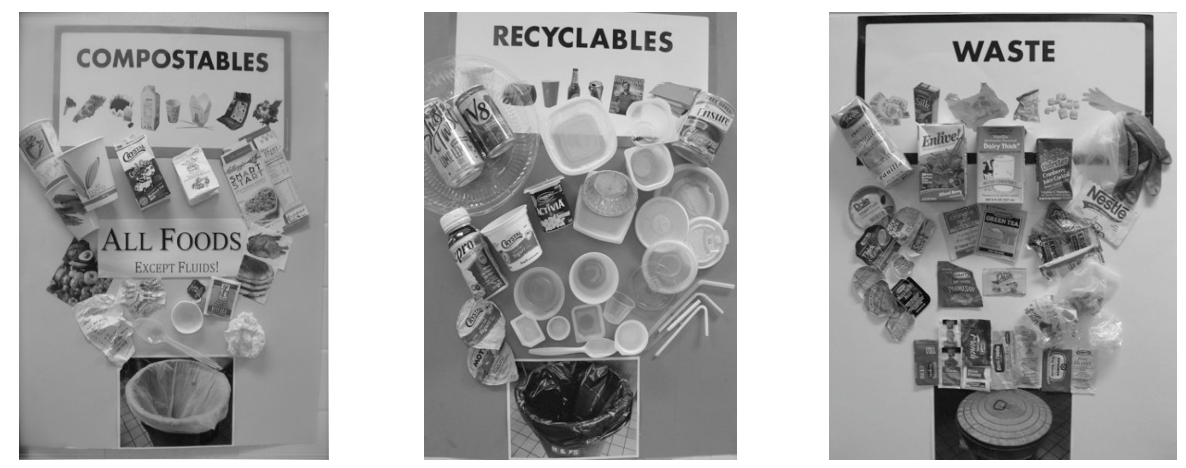

Waste diversion containers were placed throughout the kitchen, with one container for each category of waste. Compost containers were lined with biodegradable bags (BioBag, Palm Harbor, FL). Recyclable and garbage containers were of the familiar variety and lined with clear plastic bags. Although liquids (e.g. milk, soup, medical supplements) were not collected, after liquids were drained, their containers were appropriately processed. After each meal, recyclables, compost 
and garbage were removed from the kitchen. Compost was transferred to a 96-gallon cart provided by the municipal trash hauler, which was then stored outdoors on the same loading dock as recycling and trash, affording quick and easy removal of compost. After the final daily transfer to the compost cart, staff washed all kitchen waste carts. Twice per week, compostable waste was hauled away to a facility for decomposition (whose final product was later re-sold as nutrient dense soil amendment).

After training food service staff, a 2-week "trial run" of the waste diversion program began. Instead of collecting data on the amount of diverted food waste during the trial run, the intern worked with food service personnel to make sure that all procedures were being followed. After confirmation that staff was competent and fully understood procedures, data collection on the amount (in pounds) of diverted waste began the third week. Sorted waste was measured after all 3 meals Monday through Friday. Compostable and recyclable waste items were weighed using a 115-pound kitchen receiving scale (Toledo, model \#2081). Garbage was not weighed and was immediately discarded after collection. Data collection ceased after 1 week, although the waste diversion program continued and is still ongoing.

\section{RESULTS}

\section{Total Compostable and Recyclable Waste}

Over the course of 5 days of data collection, 1251 pounds of compostable food waste and 139 pounds of recyclable waste were collected and diverted. Those amounts extrapolate into 46 compostable tons and 5 recyclable tons of waste per year being diverted from municipal waste disposal. Plate waste made up $79 \%$ of the diverted waste. Recyclable matter, however, was not separately weighed with respect to place of origin within the waste stream.

There were no reported sanitation or public health problems raised in connection with the food waste diversion program. This might be due to the fact that the program essentially resulted in existing food waste merely being transferred into 3 different containers rather than 1 container. There was no reported increase in odor, while there was a decrease in reported vector control problems in the outdoor waste storage area, likely the result of food waste diversion lessening the food-related fluid seepage from the trash compactor.

\section{DISCUSSION}

This paper is the first to describe the planning and implementation of a waste diversion program in a hospital food service setting, and confirms the feasibility of such a program in a conventional cook-serve hospital kitchen. Notwithstanding the overall benefits of and growing interest in food waste diversion programs, obstacles to widespread adoption of such programs remain, including employee buy-in, space and budget limitations, and lack of coordination with municipal waste collection services. Effective means to address these obstacles must therefore be devised prior to program implementation.

In this study, food service employees were concerned with the additional time required to sort food waste on patient trays. This issue was addressed by having a program coordinator present at most meals, to assist, evaluate and offer additional education as needed during the first 3 weeks of program implementation. While one could reasonably expect this additional labor and management support at the start of the program, that extra initial support should not be relied upon over the long-term. Space limitations were addressed by first examining the flow of the kitchen, then conducting trial runs of waste collection and sorting, to maximize efficiency and use of available space while minimizing labor. Transition costs, including staff training and increased expenditures for compostable bags, were offset by waste disposal fee reductions. 
One key lesson learned was to allow for employee flexibility. For example, among the greatest challenges was sorting plate waste materials, in particular, sorting combined materials such as patient utensil kits (wrapped in soft plastic) which contained recyclable, compostable and/or garbage components. Because incorrect sorting (contamination) diminished the quality of the final composting product, staff was instructed to focus on maintaining low levels of contamination, if necessary, at the expense of collecting less compostable waste. It then became increasingly important to allow employees to devise individual separation methods. In this way, the program allowed sorting staff to adapt the process to their individual needs to keep contamination levels low while maintaining efficiency.

Sorting plate waste was identified as the largest source of contamination, which was addressed by having a monitor present during all 3 weeks to remind staff to sort with caution, and to answer questions as they arose. While staffing a coordinator at all meals is not feasible in the long-term, such monitoring at least during the training period will promote program compliance and success. With the proper training, dietetic interns can monitor during mealtimes, can provide training to new employees, and can answer service staff questions.

A smooth transition to a waste diversion program requires pre-implementation planning of many details, such as kitchen layout, materials source separation, and educational materials. Stakeholder commitment and staff participation at all levels is critical for a successful long-term waste diversion program, further underscoring the importance of ironing out such details in advance of program implementation. The volume of waste generated is greatly affected by purchasing practices (quality, packaging), food preparation and storage methods, amount of convenience foods used, menus, and patient-specific factors (census, age, gender, acuteness of illness). In addition, if the program is expanded to employee and visitor cafeterias, edible leftovers suitable for donation to local shelters should be considered.

This current study had two main limitations: 1) since a dietetic intern coordinated the program during her 3-month food service rotation, long-term follow-up was not conducted; and 2) researchers could not accurately determine the direct impact of the program on reduction in waste removal expenses since waste removal costs included the entire hospital facility.

\section{CONCLUSIONS}

Benefits of waste diversion programs include: extending the life of existing landfills (and lowering the need for new landfills); furthering the reuse of limited and diminishing resources; reducing climate gas (methane) emissions; and producing valuable soil amendments. These and other benefits counsel in favor of designing and implementing waste diversion programs for institutional food service providers. Waste diversion programs can adapt an institution's internal policies and procedures to address the growing economic, sustainability, community health and nutrition concerns, while adhering to internal or governmental mandated waste reduction goals.

The challenges of limited space, labor and equipment, as well as budget constraints and tramping up the "learning curve" will always be present. ${ }^{14}$ The presence of approximately 5700 hospitals within the US, ${ }^{7}$ however, presents an opportunity to significantly reduce the amount of MSW sent to landfills. In addition to food waste diversion programs, sustainable food service changes could include: source reduction (food packaging, inbound supply chain packaging, and operating supplies); energy and water conservation; and air quality improvement. ${ }^{3,14-17}$ Dietitians and administrators must play a central role in implementing these programs and changes within commercial and institutional facilities. ${ }^{3,14-17}$ This project showed the feasibility of a food waste diversion program to measurably reduce landfill waste and to conform to city waste diversion requirements. Over time, this program will greatly benefit the hospital by reducing expenses, improving employee morale, and building a stronger image in the community. 


\section{REFERENCES}

1. US Environmental Protection Agency. Municipal solid waste generation, recycling, and disposal in the United States: Facts and figures for 2008. Available at: http://www.epa.gov/waste/nonhaz/municipal/msw99.htm. Accessed December 8, 2009.

2. California Integrated Waste Management Board. Food scrap management. Available at http://www.ciwmb.ca.gov/foodwaste/. Accessed October 9, 2009.

3. Health Care Without Harm. About us. Available at:http://www.noharm.org/all_regions/about/. Accessed May 5, 2010.

4. Health Care Without Harm. Addressing climate change in the health care setting: Opportunities for action. Available at: http://www.noharm.org/lib/downloads/waste/ Addressing_Climate_Change.pdf. Accessed October 13, 2009.

5. US Environmental Protection Agency. Solid waste management and greenhouse gases: A lifecycle assessment of emissions and sinks. Available at: http://epa.gov/climatechange/ wycd/waste/SWMGHGreport.html. Accessed November 29, 2009.

6. Unger S, Wooten H. A food systems assessment for Oakland, CA: Toward a sustainable food plan. Available at: http://oaklandfoodsystem.pbworks.com/f/OFSA_TOC_ ExecSumm.pdf. Accessed November 29, 2009.

7. American Hospital Association. Fast facts on US hospitals. Available at: http://www.aha.org/aha/resource-center/Statistics-and-Studies/fast-facts.html. Accessed December 4, 2009.

8. Health Care Without Harm. Healthy food in health care. A pledge for fresh, local, sustainable food. http://www.noharm.org/lib/downloads/food/Healthy_Food_in_Health_Care.pdf. Accessxsed May 5, 2010.

9. Health Care Without Harm. Menu of change: Healthy food in health care. A 2008 survey of healthy food in health care pledge hospitals. Available at: http://noharm.org/us_canada/issues/food/. Accessed May 5, 2010.

10. EWRI Currents. Issues and challenges in composting food wastes. Volume 8, Number 2, Spring 2006. Available at: http://email.asce.org/ewri/CompostingFood.html. Accessed December 8, 2009.

11. City of San Francisco. sfenvironment.org website. Universal recycling and composting ordinance. Available at http://www.sfenvironment.org/downloads/library/ sf_universal_recycling_composting_ordinance.pdf. Accessed November 7, 2009.

12. SustainLane. 2008 US city rankings. Available at: http://www.sustainlane.com/us-cityrankings/categories/waste-management. Accessed December 4, 2009.

13. Toronto. Waste diversion programs. Available at: http://www.toronto.ca/garbage/programs.htm. Accessed December 4, 2009

14. Mills LS. From local chow to green machines: ADA Members are turning foodservice into ecofriendly operations. ADA Times. Jan/Feb 2008:13-17.

15. Harmon AH, Gerald BL. Position of the American Dietetic Association: Food and nutrition professionals can implement practices to conserve natural resources and support ecological sustainability. J Am Diet Assoc. 2007;107:1033-1043.

16. Donovan L. Hospital finds winning waste reduction formula. Biocycle. 1999;40:47-49.

17. Townsend WK, Cheeseman CR. Guidelines for the evaluation and assessment of the sustainable use of resources and of wastes management at healthcare facilities. Waste Manage Res. 2005;23:398-408. 